\title{
Association between Androgen Deprivation Therapy and Risk of Dementia in Men with Prostate Cancer
}

\author{
Jui-Ming Liu ${ }^{1}\left(\mathbb{D}\right.$, Chin-Yao Shen ${ }^{2}$, Wallis C. Y. Lau ${ }^{3,4}{ }^{\text {, Shih-Chieh Shao }}{ }^{2,5}$, Kenneth K. C. Man ${ }^{3,4}{ }^{\mathbb{D}}$, \\ Ren-Jun Hsu ${ }^{6,7}{ }^{(1)}$, Chun-Te $\mathrm{Wu}^{8}$ and Edward Chia-Cheng Lai ${ }^{2, *}$
}

1 Division of Urology, Department of Surgery, Taoyuan General Hospital, Ministry of Health and Welfare, Taoyuan 33004, Taiwan; mento1218@gmail.com

2 School of Pharmacy, Institute of Clinical Pharmacy and Pharmaceutical Sciences, College of Medicine, National Cheng Kung University, Tainan 70101, Taiwan; steven_shen0507@hotmail.com (C.-Y.S.); s.c.shao@hotmail.com (S.-C.S.)

3 Research Department of Practice and Policy, UCL School of Pharmacy, London WC1N 1AX, UK; wallis.lau@ucl.ac.uk (W.C.Y.L.); kenneth.man@ucl.ac.uk (K.K.C.M.)

4 Centre for Safe Medication Practice and Research, Department of Pharmacology and Pharmacy, Li Ka Shing Faculty of Medicine, The University of Hong Kong, Hong Kong

5 Department of Pharmacy, Keelung Chang Gung Memorial Hospital, Keelung 20401, Taiwan

6 Cancer Research Center, Hualien Tzu Chi Hospital, Buddhist Tzu Chi Medical Foundation, Hualien 97002, Taiwan; hsurnai@gmail.com

7 College of Medicine, Tzu Chi University, Hualien 97004, Taiwan

8 Department of Urology, Keelung Chang Gung Memorial Hospital, Keelung 20401, Taiwan; wucgmh@gmail.com

check for updates

Citation: Liu, J.-M.; Shen, C.-Y.; Lau, W.C.Y.; Shao, S.-C.; Man, K.K.C.; Hsu, R.-J.; Wu, C.-T.; Lai, E.C.-C. Association between Androgen Deprivation Therapy and Risk of Dementia in Men with Prostate Cancer. Cancers 2021, 13, 3861. https://doi.org/10.3390/ cancers13153861

Academic Editor: Vasiliki Tzelepi

Received: 21 June 2021

Accepted: 27 July 2021

Published: 31 July 2021

Publisher's Note: MDPI stays neutral with regard to jurisdictional claims in published maps and institutional affiliations.

Copyright: () 2021 by the authors. Licensee MDPI, Basel, Switzerland. This article is an open access article distributed under the terms and conditions of the Creative Commons Attribution (CC BY) license (https:// creativecommons.org/licenses/by/ $4.0 /)$.
* Correspondence: edward_lai@mail.ncku.edu.tw; Tel.: +886-6-2353535 (ext. 6209)

Simple Summary: Androgen deprivation therapy (ADT) is the gold standard treatment for advanced prostate cancer and the subsequent risk of dementia remains controversial. Previous studies were limited by small sample sizes, short follow-up times, and racial differences. In this populationbased cohort study, we used the National Health Insurance Database of Taiwan and The Health Improvement Network database of the United Kingdom to retrospectively study 129,126 men with prostate cancer in the United Kingdom (UK) and Taiwan. Compared with the ADT-naïve control, patients treated with ADT showed no significant increase in the risk of dementia in both the UK and Taiwan populations. Despite the differences in the populations of the two databases, these results suggest no association between the use of ADT and new-onset dementia.

Abstract: The risk of dementia after androgen deprivation therapy (ADT) in patients with advanced prostate cancer $(\mathrm{PCa})$ remains controversial. This study aimed to evaluate the association between ADT and the incidence of dementia in patients with PCa. We identified patients newly diagnosed with PCa in the National Health Insurance Database of Taiwan from 1 January 2002 to 30 June 2016 and in The Health Improvement Network of the United Kingdom (UK) from 1 January 1998 to 31 March 2018. We classified patients with PCa into ADT and ADT-naïve groups. Propensity score (PS) methods were used to minimize the differences in characteristics between the groups. We performed a Cox proportional hazard model to obtain the adjusted hazard ratio (HR) to compare the incidence of dementia between the groups. Our ADT group comprised 8743 and 73,816 patients in Taiwan and the UK, respectively, which were matched 1:1 to ADT-naïve patients by PS. The incidence rates of dementia in the ADT group were 2.74 versus 3.03 per 1000 person-years in the ADT naïve groups in Taiwan, and 2.81 versus 2.79 per 1000 person-years in the UK. There was no statistical difference between ADT and ADT-naïve groups (adjusted HR: 1.12; 95\% confidence interval (CI): 0.87-1.43 in Taiwan and adjusted HR: 1.02; 95\% CI: 0.85-1.23 in the UK). We found no association between the incidence of dementia and ADT in patients with advanced PCa in either database. Further studies are warranted to evaluate other possible triggers of incident dementia in patients receiving ADT for advanced PCa. 
Keywords: androgen deprivation therapy; dementia; prostate cancer; multi-database study

\section{Introduction}

Androgen deprivation therapy (ADT) has been a mainstay treatment for advanced prostate cancer (PCa) for decades [1,2]. However, ADT can reduce the level of testosterone which has been reported to be associated with a decline of a cognitive function. Moreover, a reduction in androgen may impede the modulation of $\beta$-amyloid protein accumulation, which may also affect cognition [3]. This raises concerns over an increased risk of neurodegenerative diseases such as dementia in patients with advanced PCa who receive ADT. Some studies from the United States have reported a range of a 1.17-2.17 times increased risk of dementia in patients receiving ADT for advanced PCa [4-7]. A study from Korea found a 17\% increased risk of dementia in an ADT group compared to an ADT-naïve group [8]. Jhan et al. found that ADT was associated with an $84 \%$ increase in the risk of Alzheimer's disease (AD) in the population of Taiwan [9]. Furthermore, several studies have revealed that ADT can interfere with the cardiovascular system and worsen patients' dementia [10,11]. The treatment of dementia and related symptoms, such as the use of antidementia drugs and antipsychotics, may also affect patients' circulatory system, leading to a deteriorating cycle between neurocognitive and cardiovascular events in patients with advanced PCa.

However, some studies based on populations of the United Kingdom (UK), Australia and Sweden did not support the association between ADT and dementia $[10,12,13]$. The discrepancy in the findings and conclusions of these studies could be partly explained by differences in the ethnicities of patients. Kao LT et al. used the same database as the study by Jhan et al. from Taiwan but reached an inconsistent conclusion $[9,14]$. This may reflect the fact that the findings were sensitive to variations of study design, outcome definitions and analytic approaches. In particular, compared to ADT-naïve patients, patients on ADT were generally older and more likely to be in a more severe state of $\mathrm{PCa}$, and thus at higher risk of dementia, raising the question of selection bias. Since patients who died could not develop dementia, a competing risk due to mortality may have arisen. On the other hand, since patients who could receive ADT had not died or developed dementia before they received treatment, immortal-time bias in the analysis could not be excluded from the analyses. Taking together all the possible biases in the analysis, the result estimates become unpredictable.

To date, the association between ADT and dementia remains controversial. Possible ethnic influences on the risk of dementia with ADT have not been evaluated. Our study aimed to use two population-based databases, the National Health Insurance Database (NHID) of Taiwan and The Health Improvement Network (THIN) of the UK, to verify the association between ADT and the risk of dementia in patients with PCa, as experienced by different ethnicities. Specifically, we performed a series of analyses including propensity score methods, competing risk models, and landmark methods to address the issues of potential selection bias, competing risk and immortal time bias.

\section{Materials and Methods}

\subsection{Data Sources}

We conducted a retrospective cohort study utilizing the NHID of Taiwan and the THIN database of the UK. The details of the databases are described elsewhere $[15,16]$. Briefly, the NHID is derived from Taiwan's National Health Insurance Program which covers $99.9 \%$ of the entire population of Taiwan (approximately 23 million individuals). Information on the NHID includes enrollees' demographics, health care professionals and facilities, service claims from inpatient and ambulatory care, and contracted pharmacies. The THIN contains records from over 800 practices and records of 18 million patients, covering $6.2 \%$ of the UK population. Data from THIN are demographically representa- 
tive of the UK population [15]. THIN contains information such as sociodemographic characteristics, consultations, prescriptions, and diagnoses, and has been used widely in large-scale research studies including those on dementia [17]. Diagnoses in the NHID are coded following the International Classification of Diseases, 9th or 10th revision, Clinical Modification (ICD-9-CM or ICD-10-CM). Diagnoses in THIN are coded according to the READ code. This study was approved by the Institutional Review Board of National Cheng Kung University Hospital (A-ER-107-387) and the Research Ethics Committee for THIN (19THIN084).

\subsection{Study Population}

We included patients newly diagnosed with PCa and recorded in Taiwan's NHID between 1 January 2002 and 30 June 2016, and those recorded in the UK's THIN between 1 January 1998 and 31 March 2018. We confirmed the diagnosis of PCa by ICD-9-CM 185 and ICD-10-CM C61 codes in the NHID and by READ codes in the THIN database (Table S1) $[18,19]$. The index date of each PCa patient in the ADT group was defined as the first date of filling a prescription for ADT. The index date of each patient in the ADT-naïve group was the diagnosis date of PCa. We excluded patients aged 40 years and younger at an index date. Patients who had any record of dementia diagnosis, or any kind of cancer were removed from the analysis. We excluded patients diagnosed with dementia within 6 months after the index date since the occurrence of dementia was unlikely to be related to ADT. We also excluded patients without a minimum of 6 months follow-up to ensure that all study samples had a sufficient observation period. The flowchart of the study population selection is presented in Figure 1A,B.

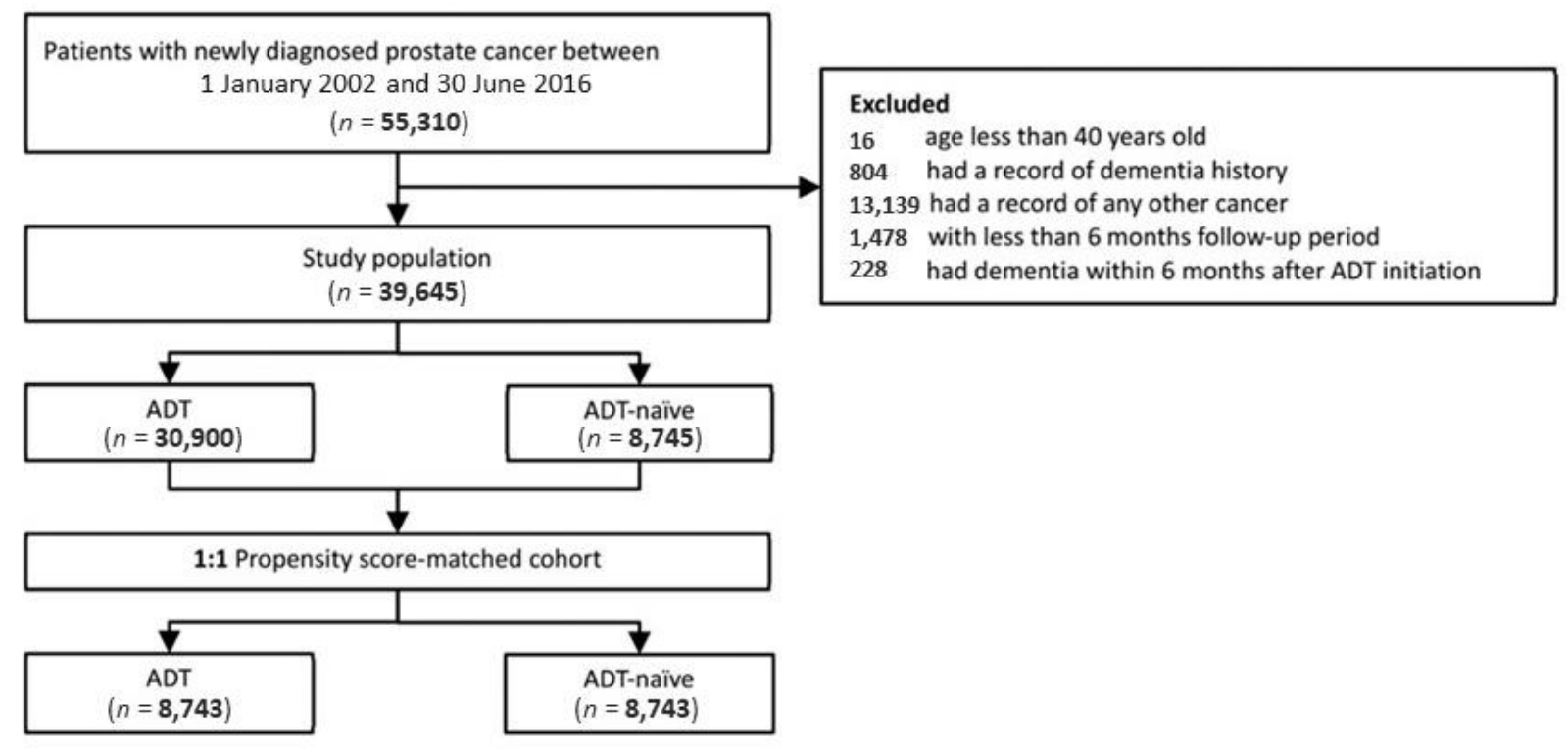

(A)

Figure 1. Cont. 


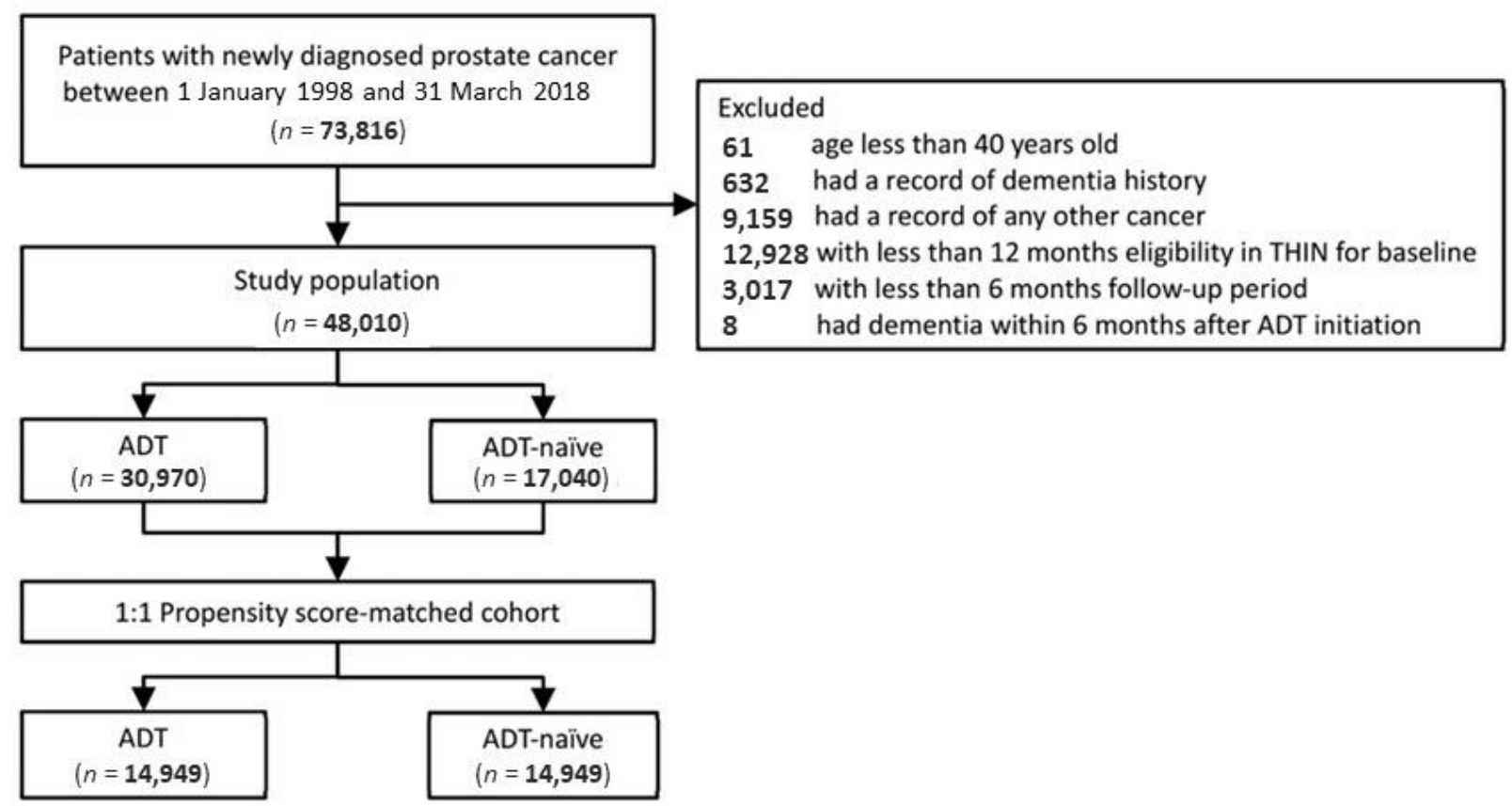

(B)

Figure 1. Study cohort selection flowchart: (A) the NHID of Taiwan; (B) the THIN database of the UK. ADT: androgen deprivation therapy; NHID: National Health Insurance Database; THIN: The Health Improvement Network; UK: United Kingdom.

\subsection{Exposures and Outcomes}

We classified patients into two study groups, the ADT- and ADT-naïve groups according to the records of treatment for advanced PCa. ADT included the use of GnRH agonists (leuprolide, goserelin, triptorelin, and buserelin); oral antiandrogens (cyproterone acetate, bicalutimide, flutamide, and nilutamide); estrogens (diethylstilbestrol and estramustine); and bilateral orchiectomy (Table S2). The study outcome was the incidence of dementia, defined as the first date when the patient received both dementia diagnosis and anti-dementia medication. The diagnosis was defined by the ICD-9 code / ICD-10 code in the NHID (Table S3) and the READ code in the THIN database (Table S4) [17]. The ATC code was used to define anti-dementia agents in both Taiwan and the UK (Tables S3 and S4).

A record of the subsequent use of antidementia drugs was confirmed in order to improve the validity of dementia diagnosis (Table S3). We followed up patients from the index date to the date of diagnosis of dementia, death or the last day of the databases, whichever came first.

\subsection{Covariates}

Baseline covariates were captured covering one year preceding the index date. The covariates consisted of the patients' age at index date, comorbidities (e.g., hypertension, coronary heart disease, heart failure, atrial fibrillation, peripheral arterial disease, ischemic stroke, diabetes mellitus, chronic obstructive pulmonary disease, chronic kidney disease, chronic liver disease, traumatic brain injury, and depression) and co-medications (e.g., oral hypoglycemic agents, insulin, antiplatelets, anticoagulants, antihypertensive medications, calcium channel blockers, beta-blockers, angiotensin-converting enzyme inhibitors or angiotensin II receptor blockers, non-steroidal anti-inflammatory drugs, cyclooxygenase-2 inhibitors, statins, antidepressants, antipsychotics, and benzodiazepines). 


\subsection{Statistical Analysis}

We described continuous variables by mean with a standard deviation, and categorical variables by numbers with proportions. We used the standardized mean difference to assess the difference in baseline characteristics between groups. We performed propensity score methods with the matching technique (1:1) to create more comparable groups at the baseline between the ADT and ADT-naïve groups. The propensity score was a predicted probability of being in the ADT group, given the baseline covariates listed in Table 1. Age was included as a categorical variable $(<65 \mathrm{y}, 65-74 \mathrm{y}, 75-84 \mathrm{y}, \geq 85 \mathrm{y})$ in the propensity score modelling. We used Kaplan-Meier survival curves along with a log-rank test to compare time to outcome events between groups. We used the Cox proportional hazard model to obtain the adjusted hazard ratios (HR) with a $95 \%$ confidence interval (CI) for the comparison of dementia risk between the groups.

Table 1. Characteristics of the study patients.

\begin{tabular}{|c|c|c|c|c|c|c|}
\hline \multirow[b]{2}{*}{ Covariates } & \multicolumn{3}{|c|}{ Taiwan } & \multicolumn{3}{|c|}{ UK } \\
\hline & ADT & $\begin{array}{l}\text { ADT- } \\
\text { Naïve }\end{array}$ & SMD & ADT & $\begin{array}{l}\text { ADT- } \\
\text { Naïve }\end{array}$ & SMD \\
\hline Number of patients & 8743 & 8743 & & 14,949 & 14,949 & \\
\hline Age, y (SD) & $70.3(8.9)$ & $69.8(8.9)$ & 0.06 & $70.0(8.5)$ & $69.2(8.8)$ & 0.10 \\
\hline \multicolumn{7}{|l|}{ Age group, $\mathrm{y}, n(\%)$} \\
\hline$<65$ & $2510(28.7)$ & $2471(28.3)$ & 0.06 & $4525(30.3)$ & $4484(30.0)$ & 0.02 \\
\hline $65-74$ & $3581(41.0)$ & $3643(41.7)$ & & $6738(45.1)$ & $6830(45.7)$ & \\
\hline $75-84$ & $2181(24.9)$ & $2180(24.9)$ & & 2965 (19.8) & $2966(19.8)$ & \\
\hline$\geq 85$ & $471(5.4)$ & $449(5.1)$ & & $721(4.8)$ & $669(4.5)$ & \\
\hline \multicolumn{7}{|l|}{ Comorbidity, $n(\%)$} \\
\hline Hypertension & $4597(52.6)$ & $4528(51.8)$ & 0.02 & $5956(39.8)$ & $6074(40.6)$ & -0.02 \\
\hline Coronary heart disease & 1659 (19.0) & $1700(19.4)$ & -0.01 & $2278(15.2)$ & $2252(15.1)$ & 0.005 \\
\hline Heart failure & $348(4.0)$ & $315(3.6)$ & 0.02 & $457(3.1)$ & 489 (3.3) & -0.01 \\
\hline Atrial fibrillation & $199(2.3)$ & $208(2.4)$ & -0.01 & $846(5.7)$ & $878(5.9)$ & -0.01 \\
\hline $\begin{array}{c}\text { Peripheral arterial } \\
\text { disease }\end{array}$ & $247(2.8)$ & $255(2.9)$ & -0.01 & $439(2.9)$ & $454(3.0)$ & -0.01 \\
\hline Ischemic stroke & $851(9.7)$ & $868(9.9)$ & -0.01 & $509(3.4)$ & $498(3.3)$ & 0.004 \\
\hline Diabetes mellitus & $1804(20.6)$ & $1896(21.7)$ & -0.03 & $1502(10.0)$ & 1577 (10.5) & -0.02 \\
\hline $\begin{array}{l}\text { Chronic obstructive } \\
\text { pulmonary disease }\end{array}$ & $1087(12.4)$ & $1086(12.4)$ & $<0.001$ & $828(5.5)$ & $791(5.3)$ & 0.01 \\
\hline Chronic kidney disease & 1037 (11.9) & $1054(12.1)$ & -0.01 & $1256(8.4)$ & $1311(8.8)$ & -0.01 \\
\hline Chronic liver disease & 1119 (12.8) & 1128 (12.9) & $<-0.001$ & $252(1.7)$ & $284(1.9)$ & -0.02 \\
\hline Traumatic brain injury & $155(1.8)$ & $139(1.6)$ & 0.01 & $143(1.0)$ & $172(1.2)$ & -0.02 \\
\hline Depression & $278(3.2)$ & $301(3.4)$ & -0.01 & $2132(14.3)$ & $2236(15.0)$ & -0.02 \\
\hline \multicolumn{7}{|l|}{ Co-medication, $n(\%)$} \\
\hline NSAID & $6414(73.4)$ & $6418(73.4)$ & $<-0.001$ & 3198 (21.4) & $3296(22.0)$ & -0.02 \\
\hline Aspirin & $2043(23.4)$ & $2078(23.8)$ & -0.01 & $3532(23.6)$ & $3530(23.6)$ & $<0.001$ \\
\hline Clopidogrel & $317(3.6)$ & $313(3.6)$ & $<0.001$ & $383(2.6)$ & $410(2.7)$ & -0.01 \\
\hline COX-2 inhibitor & $888(10.2)$ & $896(10.2)$ & $<-0.001$ & $229(1.5)$ & $237(1.6)$ & -0.004 \\
\hline Anticoagulant agents & $149(1.7)$ & $150(1.7)$ & $<-0.001$ & $662(4.4)$ & $688(4.6)$ & -0.01 \\
\hline Statin & 1705 (19.5) & $1790(20.5)$ & -0.02 & $5027(33.6)$ & $5136(34.4)$ & -0.02 \\
\hline $\begin{array}{l}\text { Oral hypoglycemic } \\
\text { agents }\end{array}$ & $1463(16.7)$ & $1531(17.5)$ & -0.02 & $978(6.5)$ & $1006(6.7)$ & -0.01 \\
\hline Insulin & $306(3.5)$ & $326(3.7)$ & -0.01 & $211(1.4)$ & $228(1.5)$ & -0.01 \\
\hline $\mathrm{ACEi} / \mathrm{ARB}$ & $3041(34.8)$ & $3037(34.7)$ & $<0.001$ & $4438(29.7)$ & $4565(30.5)$ & -0.02 \\
\hline Antidepressants & 1192 (13.6) & $1223(14.0)$ & -0.01 & $1528(10.2)$ & $1582(10.6)$ & -0.01 \\
\hline Antipsychotics & $729(8.3)$ & $729(8.3)$ & $<0.001$ & $437(2.9)$ & $466(3.1)$ & -0.01 \\
\hline Benzodiazepines & $3420(39.1)$ & $3561(40.7)$ & -0.03 & $1189(8.0)$ & $1212(8.1)$ & -0.01 \\
\hline Beta-blocker & $2216(25.3)$ & $2253(25.8)$ & -0.01 & $2530(16.9)$ & 2567 (17.2) & -0.01 \\
\hline $\mathrm{CCB}$ & 3265 (37.3) & $3210(36.7)$ & 0.01 & 3318 (22.2) & 3359 (22.5) & -0.01 \\
\hline $\begin{array}{l}\text { Follow-up years, } y \text {, mean } \\
\text { (SD) }\end{array}$ & $4.3(2.2,7.3)$ & $4.2(2.1,7.2)$ & 一 & $5.3(4.0)$ & $5.6(4.1)$ & \\
\hline
\end{tabular}

ACEi: angiotensin-converting enzyme inhibitor; ADT: androgen deprivation therapy; ARB: angiotensin receptor blocker; CCB: calcium channel blocker; COX-2 inhibitor: cyclooxygenase-2 inhibitors; NSAID: non-steroidal anti-inflammatory drugs; SD: standard deviation; SMD: standardized mean difference. 


\subsection{Sub-Analysis and Sensitivity Analysis}

Patients were classified into several subgroups by different types of ADT (i.e., GnRH agonist-based treatment or oral antiandrogens only) and by duration of ADT use $(<6,6-12$, $13-18,19-24$ and $24+$ months) for sub-analysis. We conducted a series of sensitivity analyses to examine the robustness of the results. First, we used the propensity score with inverse probability of treatment weighting (IPTW) and standardized mortality ratio weighting (SMRW) to create homogeneous groups for comparisons. We performed both IPTW and SMRW methods because the estimates from IPTW reflected the average treatment effects in the population, while the SMRW generated average treatment effects in treated patients [20]. Because the study samples could be old and sensitive to a competing risk of mortality, we used cause-specific hazard model and a sub-distribution hazard model to assess the influence from competing effects due to mortality [21]. Moreover, to address the issue of immortal-time bias in the analysis, we used the landmark method with 1- and 2-year landmark periods, to reduce the influence of the bias and to estimate the results [22]. We conducted all analyses using SAS version 9.4 (SAS Institute, Cary, NC, USA).

\section{Results}

We identified a total of 8743 and 73,816 patients in the ADT group, in Taiwan and in the UK, respectively, which matched the same numbers of ADT-naïve patients by PS. The distribution of baseline covariates between the ADT group and ADT naïve groups was similar (SMD $<10 \%$ ) in both countries after propensity score matching. The mean age was 70.3 years (SD 8.9) in the ADT group and 69.8 (SD 8.9) years in the matched ADT-naïve patients in Taiwan, and 70.0 years (SD 8.5) and 69.2 years (SD 8.7), respectively, in the UK. The rates of diabetes mellitus were $20.6 \%$ and $21.7 \%$ for ADT and the matched ADT naïve groups, respectively, in Taiwan, but only $10.0 \%$ and $10.5 \%$, respectively, in the UK; the rates of benzodiazepine use were $39.1 \%$ and $40.7 \%$ for the ADT and ADT-naïve groups, respectively, in Taiwan, but only $8.0 \%$ and $8.1 \%$, respectively, in the UK. The details of patients' baseline characteristics are presented in Table 1.

The Kaplan-Meier curves for the analyses of Taiwan and the UK are presented in Figure 2A,B, respectively. The overall incidence rates of dementia in the ADT group were 2.74 versus 3.03 per 1000 person-years in the matched ADT-naïve group in Taiwan, and 2.81 versus 2.79 per 1000 person-years, respectively, in the UK. There was no statistically significant difference between the ADT group and the matched ADT-naïve group (adjusted HR: 1.12; 95\% CI: $0.87-1.43$ in Taiwan and adjusted HR: 1.02; 95\% CI: 0.85-1.23 in the UK). The results of subgroup analyses were largely consistent with the main analysis and between countries, as listed in Table 2. There was no difference in the risk of dementia between the ADT and the matched ADT-naïve group within the subgroups of patients receiving GnRH-based therapy (adjusted HR: 0.78; 95\% CI: 0.59-1.05 in Taiwan and adjusted HR: 0.99 ; 95\% CI: $0.83-1.2$ in the UK) or oral antiandrogens only (adjusted HR: 4.18 ; 95\% CI: $0.93-1.49$ in Taiwan and adjusted HR: $1.15 ; 95 \%$ CI: $0.77-1.74$ in the UK). 
(A)

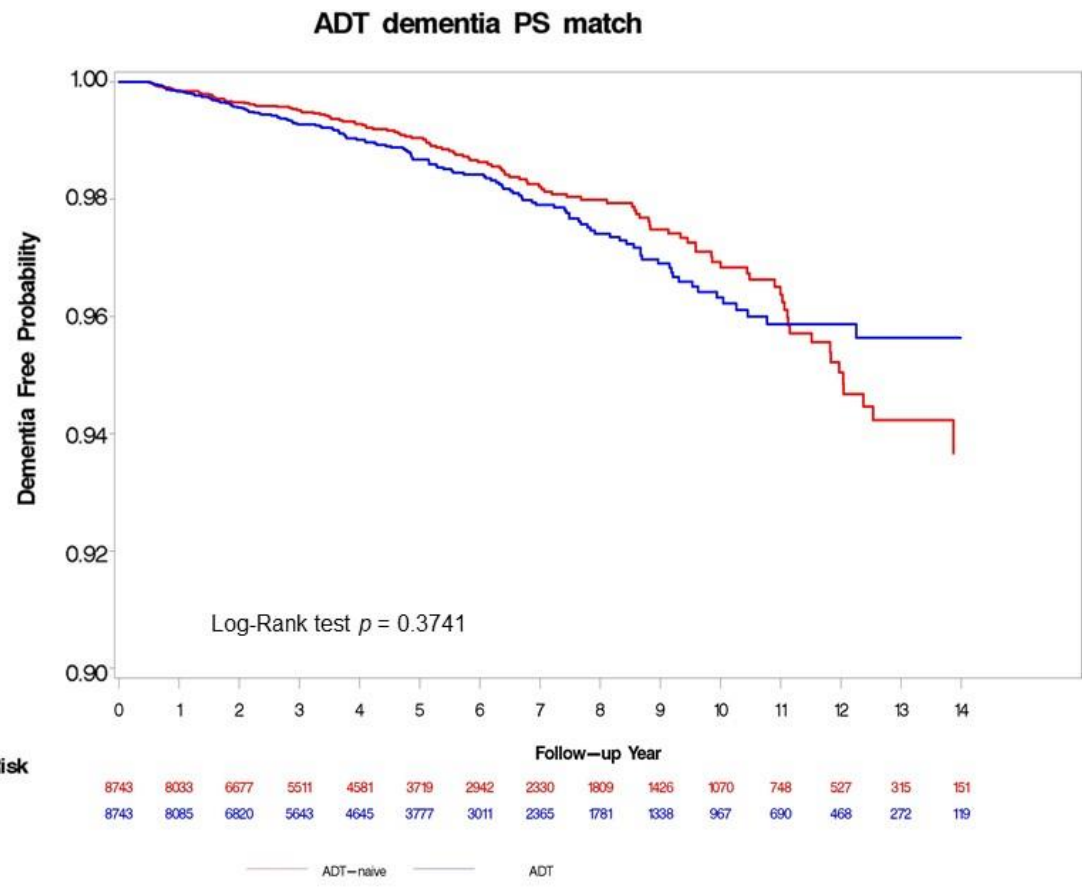

(B) ADT dementia PS match

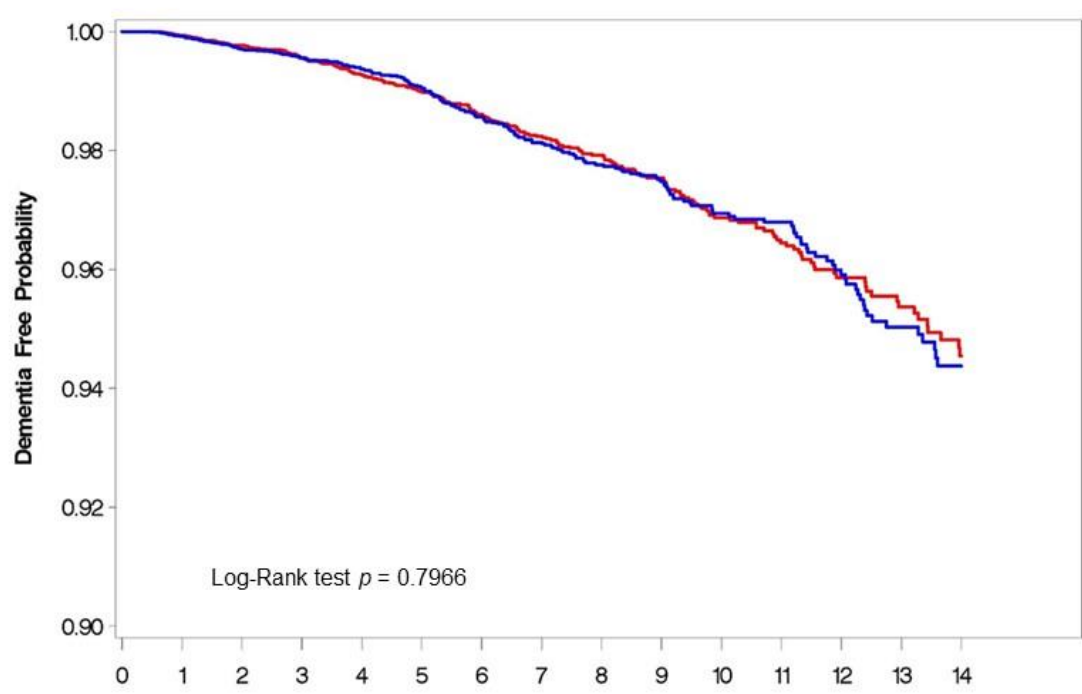

Number at Risk

Follow-up Year

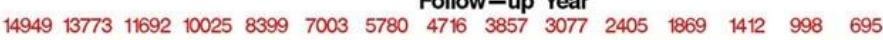

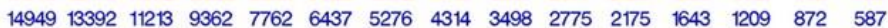

$$
\text { ADT-naive } \quad \text { ADT }
$$

Figure 2. Kaplan-Meier curves according to androgen deprivation therapy (ADT) use for the cumulative probability of remaining dementia-free in the propensity score-matched analysis: (A) Taiwan; and (B) UK. ADT: androgen deprivation therapy; PS: propensity score; UK: United Kingdom. 
Table 2. Evaluation of the association between androgen deprivation therapy and the incidence of dementia.

\begin{tabular}{|c|c|c|c|c|c|c|c|c|c|c|}
\hline & \multicolumn{5}{|c|}{ Taiwan } & \multicolumn{5}{|c|}{ UK } \\
\hline & Patients & Events & $\begin{array}{c}\text { Follow-Up } \\
\text { (Person-Years) }\end{array}$ & $\begin{array}{c}\text { Incidence Rate } \\
\quad \text { (per } 10^{3} \\
\text { Person-Years) }\end{array}$ & $\begin{array}{l}\text { Adjusted HR } \\
\text { (95\% CIs) }\end{array}$ & Patients & Events & $\begin{array}{c}\text { Follow-Up } \\
\text { (Person-Years) }\end{array}$ & $\begin{array}{c}\text { Incidence Rate } \\
\text { (per } 10^{3} \text { Person-Years) }\end{array}$ & $\begin{array}{l}\text { Adjusted HR } \\
\text { (95\% CIs) }\end{array}$ \\
\hline ADT-naïve group & 8743 & 121 & $44,181.7$ & 2.74 & Reference & 14,949 & 237 & $84,331.1$ & 2.81 & Reference \\
\hline ADT group & 8743 & 134 & $44,291.4$ & 3.03 & $1.12(0.87,1.43)$ & 14,949 & 220 & $78,765.1$ & 2.79 & $1.02(0.85,1.23)$ \\
\hline \multicolumn{11}{|c|}{ Subgroup Analysis by Type of ADT } \\
\hline \multicolumn{11}{|c|}{ GnRH agonist-based ADT } \\
\hline ADT group & 8461 & 75 & $36,614.8$ & 2.05 & $0.78(0.59,1.05)$ & 14,440 & 212 & $75,733.0$ & 2.80 & $0.99(0.83,1.20)$ \\
\hline \multicolumn{11}{|c|}{ Oral antiandrogens only } \\
\hline ADT-naïve group & 7087 & 114 & $35,523.9$ & 3.21 & Reference & 2921 & 44 & $15,909.1$ & 2.77 & Reference \\
\hline ADT group & 7087 & 171 & $42,947.8$ & 3.98 & $1.18(0.93,1.49)$ & 2921 & 48 & $14,827.8$ & 3.24 & $1.15(0.77,1.74)$ \\
\hline \multicolumn{11}{|c|}{ Subgroup Analysis by Duration of ADT } \\
\hline \multicolumn{11}{|l|}{$<6$ months } \\
\hline ADT-naïve group & 3792 & 68 & $18,420.9$ & 3.69 & Reference & 10,577 & 184 & $57,378.2$ & 3.21 & Reference \\
\hline $\begin{array}{l}\text { ADT group } \\
\text { 6-12 months }\end{array}$ & 3792 & 37 & $12,844.8$ & 2.88 & $0.88(0.59,1.32)$ & 10,577 & 161 & $44,899.3$ & 3.59 & $1.14(0.93,1.41)$ \\
\hline ADT-naïve group & 1928 & 39 & $10,112.9$ & 3.86 & Reference & 4040 & 71 & $21,181.0$ & 3.35 & Reference \\
\hline \multirow{2}{*}{\multicolumn{11}{|c|}{ 19-24 months }} \\
\hline & & & & & & & & & & \\
\hline ADT-naïve group & 1807 & 33 & $10,056.5$ & 3.28 & Reference & 2158 & 39 & $11,252.8$ & 3.47 & Reference \\
\hline $\begin{array}{l}\text { ADT group } \\
>24 \text { months }\end{array}$ & 1807 & 23 & 6775.2 & 3.40 & $1.19(0.70,2.05)$ & 2158 & 44 & $12,301.5$ & 3.58 & $1.21(0.78,1.89)$ \\
\hline ADT-naïve group & 5287 & 87 & $32,687.3$ & 2.66 & Reference & 4769 & 87 & $26,349.6$ & 3.30 & Reference \\
\hline ADT group & 5287 & 42 & $30,348.2$ & 1.38 & $0.59(0.40,0.85)$ & 4769 & 108 & $41,467.0$ & 2.60 & $0.68(0.52,0.91)$ \\
\hline
\end{tabular}

ADT: androgen deprivation therapy; CI: confidence interval; GnRH: gonadotropin-releasing hormone; HR: hazard ratio. 
The sensitivity analyses showed results consistent with the main analysis, including the analysis using PS with IPTW (adjusted HR: 0.91; 95\% CI: 0.76-1.09 in Taiwan; adjusted HR: 0.99 ; 95\% CI: $0.86-1.14$ in the UK) and SMRW (adjusted HR: 1.03; 95\% CI: $0.90-1.17$ in Taiwan; adjusted HR: 0.98 ; $95 \%$ CI: $0.87-1.10$ in the UK). The analyses using a cause-specific hazard model (adjusted HR: 1.12; 95\% CI: 0.88-1.43 in Taiwan; adjusted HR: 1.02; 95\% CI: 0.85-1.23 in the UK), sub-distribution hazard model (adjusted HR: 0.93; 95\% CI: 0.73-1.20 in Taiwan; adjusted HR: 0.85 ; $95 \%$ CI: $0.71-1.02$ in the UK), by a 1 y landmark period (adjusted HR: 0.98; 95\% CI: 0.74-1.29 in Taiwan; adjusted HR: 1.12; 95\% CI: 0.95-1.32 in the UK), and by 2-year landmark analysis (adjusted HR: 1.07; 95\% CI: 0.80-1.44 in Taiwan; adjusted HR: 1.00 ; $95 \%$ CI: $0.84-1.20$ in the UK) indicated no difference in the incidence rate of dementia between the ADT group and matched ADT-naïve group (Table 3).

Table 3. Sensitivity analysis.

\begin{tabular}{|c|c|c|c|c|c|c|c|c|c|c|}
\hline & \multicolumn{5}{|c|}{ Taiwan } & \multicolumn{5}{|c|}{ UK } \\
\hline & Patients & Events & $\begin{array}{l}\text { Follow- } \\
\text { Up } \\
\text { (Person- } \\
\text { Years) }\end{array}$ & $\begin{array}{c}\text { Incidence } \\
\text { Rate } \\
\text { (per } 10^{3} \\
\text { Person- } \\
\text { Years) }\end{array}$ & $\begin{array}{l}\text { Adjusted } \\
\text { HR (95\% } \\
\text { CIs) }\end{array}$ & Patients & Events & $\begin{array}{l}\text { Follow- } \\
\text { Up } \\
\text { (Person- } \\
\text { Years) }\end{array}$ & $\begin{array}{c}\text { Incidence } \\
\text { Rate } \\
\text { (per } 10^{3} \\
\text { Person- } \\
\text { Years) }\end{array}$ & $\begin{array}{l}\text { Adjusted } \\
\text { HR (95\% } \\
\text { CIs) }\end{array}$ \\
\hline $\begin{array}{c}\text { Analysis by PS with } \\
\text { multivariate adjustment } \\
\text { ADT-naïve group }\end{array}$ & 8745 & 121 & $44,190.8$ & 2.74 & & 17,040 & 243 & $97,787.1$ & 2.48 & \multirow{2}{*}{$\begin{array}{c}\text { Reference } \\
1.02(0.87, \\
1.19)\end{array}$} \\
\hline ADT group & 30,900 & 513 & $149,436.5$ & 3.43 & $\begin{array}{c}\text { Reference } \\
0.98(0.80 \\
1.20)\end{array}$ & 30,970 & 525 & $150,495.2$ & 3.49 & \\
\hline $\begin{array}{c}\text { Analysis by PS with IPTW } \\
\text { ADT-naïve group }\end{array}$ & 8780.4 & 156.4 & $42,884.6$ & 3.65 & \multirow{2}{*}{$\begin{array}{c}\text { Reference } \\
0.91(0.76, \\
1.09)\end{array}$} & 17,199 & 296 & $92,189.7$ & 3.21 & \multirow{2}{*}{$\begin{array}{c}\text { Reference } \\
0.99(0.86 \\
1.14)\end{array}$} \\
\hline ADT group & 30,882 & 494.0 & $150,845.5$ & 3.27 & & 30,912 & 484 & $156,175.6$ & 3.09 & \\
\hline \multicolumn{11}{|l|}{$\begin{array}{c}\text { Analysis by PS with } \\
\text { SMRW }\end{array}$} \\
\hline ADT-naïve group & $24,442.8$ & 414.5 & $121,389.2$ & 3.41 & \multirow{2}{*}{$\begin{array}{c}\text { Reference } \\
1.03(0.90 \\
1.17)\end{array}$} & 29,596 & 575 & $156,092.1$ & 3.68 & \multirow{2}{*}{$\begin{array}{c}\text { Reference } \\
0.98(0.87 \\
1.10)\end{array}$} \\
\hline ADT group & 30,900 & 513.0 & $149,436.5$ & 3.43 & & 30,970 & 525 & $150,495.2$ & 3.49 & \\
\hline \multicolumn{11}{|l|}{$\begin{array}{l}\text { Cause-specific hazard } \\
\text { model }\end{array}$} \\
\hline ADT-naïve group & 8743 & 121 & $44,181.7$ & 2.74 & \multirow{2}{*}{$\begin{array}{c}\text { Reference } \\
1.12(0.88, \\
1.43)\end{array}$} & 14,949 & 237 & $84,331.1$ & 2.81 & \multirow{2}{*}{$\begin{array}{c}\text { Reference } \\
1.02(0.85, \\
1.23)\end{array}$} \\
\hline ADT group & 8743 & 134 & $44,291.4$ & 3.03 & & 14,949 & 220 & $78,765.1$ & 2.79 & \\
\hline \multicolumn{11}{|l|}{$\begin{array}{l}\text { Sub-distribution hazard } \\
\text { model }\end{array}$} \\
\hline ADT-naïve group & 8743 & 121 & $44,181.7$ & 2.74 & \multirow{2}{*}{$\begin{array}{c}\text { Reference } \\
0.93(0.73 \\
1.20)\end{array}$} & 14,949 & 237 & $84,331.1$ & 2.81 & \multirow{2}{*}{$\begin{array}{c}\text { Reference } \\
0.85 \\
(0.71,1.02)\end{array}$} \\
\hline ADT group & 8743 & 134 & $44,291.4$ & 3.03 & & 14,949 & 220 & $78,765.1$ & 2.79 & \\
\hline $\begin{array}{l}\text { 1-year landmark period } \\
\text { ADT-naïve group }\end{array}$ & 11,903 & 199 & $80,477.0$ & 2.47 & \multirow{2}{*}{$\begin{array}{c}\text { Reference } \\
1.12(0.95 \\
1.32)\end{array}$} & 15,738 & 283 & $91,334.5$ & 3.099 & \multirow{2}{*}{$\begin{array}{c}\text { Reference } \\
1.12(0.95, \\
1.32)\end{array}$} \\
\hline ADT group & 11,903 & 180 & $67,640.7$ & 2.66 & & 15,738 & 275 & $82,845.1$ & 3.319 & \\
\hline $\begin{array}{l}\text { 2-year landmark period } \\
\text { ADT-naïve group }\end{array}$ & 9382 & 161 & $70,109.1$ & 2.30 & Reference & 12,885 & 244 & $72,094.0$ & 3.38 & Reference \\
\hline ADT group & 9382 & 138 & $61,166.0$ & 2.26 & $\begin{array}{l}1.16(0.93 \\
1.47)\end{array}$ & 12,885 & 218 & $66,517.8$ & 3.28 & $\begin{array}{l}1.003 \\
(0.84 \\
1.20)\end{array}$ \\
\hline
\end{tabular}

ADT: androgen deprivation therapy; CI: confidence interval; HR: hazard ratio; IPTW: inverse-probability-of-treatment weighting; PS: propensity score; SMRW: standardized mortality ratio weighting.

\section{Discussion}

In this multi-country population-based study, we evaluated the risk of new-onset dementia subsequent to ADT in 129,126 men with PCa in the UK and Taiwan. Compared to the ADT-naïve control, patients treated with ADT suffered no significant increase in the risk of dementia in both the NHID of Taiwan and the THIN database of the UK. A subgroup analysis showed that a longer duration of ADT did not appear to increase the risk of dementia in either the NHID or THIN databases. Despite the different populations 
of the two databases, these results suggest no association between the use of ADT and new-onset dementia.

The association between ADT and the incidence of dementia has been discussed for years. Some studies have indicated that the reduced testosterone level $[10,13,23]$ from ADT leads to poor performance in terms of visual memory, verbal memory, and visuospatial rotation in healthy older men $[3,24]$. However, other studies have failed to deliver any evidence of substantial change in cognitive function after a decrease in testosterone levels $[25,26]$. A recent meta-analysis showed that ADT use in prostate cancer patients did not increase the risk of cognitive impairment [27]. However, other metaanalysis studies provided inconclusive evidence of cognitive impairment after ADT use [28]. Because dementia is a latent and progressive neurodegenerative disease that is hard to observe, detection bias or misclassification of outcomes in studies are hard to avoid. Compared to the ADT-naïve group, patients who received ADT were more likely to be under observation or have signs or symptoms of dementia detected, since they routinely returned to clinics, which may explain the association found in some studies $[4-7,29]$. In our study, we used the diagnosis codes combined with records of the subsequent use of dementia drugs to improve the validity of our analysis. The results may reflect the outcome of overt dementia requiring treatment, while minimizing potential bias due to varying levels of detection of relatively mild dementia.

Men receiving ADT may experience body weight loss, fatigue, reduced physical activity or increased risk of fracture [30], which may greatly affect the patients' social networking or mental condition. Although reports have indicated that these side effects could be contributing factors to the outcome of dementia, our study did not find an association between ADT and the incidence of dementia. This may suggest that the side effects did not substantially affect the outcome of dementia. The efficacy of ADT has been demonstrated from RCT and observational studies [31,32], however, the maintenance of the good quality of life and patients' social network after ADT are also important in patients with advanced PCa. Future investigations into the changes in the quality of life and social behaviors after ADT treatment for advanced PCa patients are warranted, to provide better fundamental information to improve patients' outcomes.

Previous studies have provided inconsistent results regarding the association between ADT and dementia in men with advanced PCa [7,10,14,33-36], possibly because of the differences in study designs, outcome definitions or population ethnicities. Our study was specifically designed to address issues that might affect the analysis. We used propensity score methods to create comparable groups at baseline to minimize selection bias. We defined dementia by diagnosis code combined with the subsequent use of dementia medication to improve the validity of the analysis. Cause-specific hazard and sub-distribution hazard analysis were implemented to address competing risk due to mortality [21]. We adopted landmark methods to minimize immortal time bias [22]. We specifically used two large population-based databases from Taiwan and the UK, composed of different ethnicities to reaffirm the association. It has been reported that patients typically receive ADT for two to three years, based on the guidelines for long-term ADT (28-36 months) in prostate cancer [37]. We found that the rates of patients receiving ADT for more than 24 months were $60.5 \%$ in Taiwan but only $31.9 \%$ in the UK. To address the possible issue of duration of ADT, we stratified patients by different durations and examined the association with incident dementia. However, we did not find any cumulative dose-response relationship with the dementia risk among patients receiving ADT of various durations.

There seemed to be a higher prevalence of comorbidities in the Taiwan cohort than the UK cohort. This may be due to actual differences in the disease prevalence between the different ethnicities, or partly the result of differences in the healthcare systems and coding practices between Taiwan and the UK. Taiwan uses a health insurance system, the National Health Insurance (NHI), which covers $99.9 \%$ of the 23 million residents of Taiwan [38]. The UK uses a publicly funded, universal healthcare system where over $98 \%$ of the UK population are registered with a primary care general practitioner [39]. The 
NHID of Taiwan is an insurance claims database, while the UK's THIN is a primary care database, and both are nationally representative. The needs of the different healthcare systems could lead to different coding practices in the databases.

In contrast, we observed a higher prevalence of depression in our UK cohort, while the Taiwanese were more likely to be on antidepressants. In general, Asian countries are reported to have lower prevalence rates for depression - between 2 and 5 percent; compared to Western countries-with a higher prevalence of around 10 to 15 percent [40]. The higher use of antidepressants in Taiwan could be due to antidepressants being prescribed for other indications such as sleep aid and chronic pain in cancer patients. For example, tricyclic antidepressants can be prescribed for chronic pain. Trazodone is the second most commonly used antidepressant in Taiwan, which is most frequently prescribed for insomnia [41]. In addition, trazodone may be prescribed to improve erectile function [42] to treat erectile dysfunction caused by ADT in patients with prostate cancer. Benzodiazepine use is higher in Taiwan compared to other Asian countries, as reported by the Research on Asian Psychotropic Prescription Patterns for Antidepressants database [43]. This could be due to higher insurance coverage, easy access to psychotropic medication, low medication costs, and psychopharmacological prescription traditions in Taiwan.

Although there were some differences in the patients' characteristics between the two countries' populations, we obtained consistent results from both countries, whereby no association between ADT and the incidence of dementia was found. The results were further examined by a series of analyses and showed good robustness. The analysis also showed no cumulative dose relationship and no duration relationship through the use of ADT, with the incidence of dementia. This study included two nationwide databases from Taiwan and the UK, delivering consistent results, and the findings are useful to generalize to both Asian and Western populations.

There were several limitations to this study. First, indicators for the severity of advanced PCa such as PSA levels, clinical stages of prostate cancer, and Gleason scores were not available from the databases; hence, confounding by indication remained possible. Second, indicators for the assessment of cognitive functions such as mini-mental status examination and clinical dementia rating scores were not available. No inference on the association between ADT and different degrees of severity of dementia can be made from this study. Third, because propensity scores were derived based on observed covariates, residual confounders such as patients' body mass index, lipid profiles and inflammation parameters, which are unmeasurable by the claims database, were not addressed in this study. Due to the study design, the comorbidities and comedications of the UK and Taiwan populations differed on account of their different ethnicities, treatment costs, and health insurance policies, all of which could not be examined. Comparisons between the two countries should be made carefully, because the features of the databases, healthcare systems, cultures and characteristics of the populations vary substantially between countries. Nevertheless, we found similar incidence rates of dementia and consistent study results from both populations.

\section{Conclusions}

The study demonstrated that the treatment of patients with ADT for advanced PCa was not associated with a higher risk of dementia in both UK and Taiwan populations. We did not find any cumulative dose effect between ADT and dementia. Further studies are warranted to evaluate other possible triggers of dementia in patients receiving ADT for advanced PCa.

Supplementary Materials: The following are available online at https: / www.mdpi.com/article/ 10.3390/ cancers13153861/s1, Table S1: The ICD-9 / ICD-10 codes of prostate cancer in Taiwan and READ codes in the UK, Table S2: ATC codes for medicines for androgen deprivation therapy, Table S3: ICD-9 codes, ICD-10 codes and ATC codes for identifying dementia in the Taiwan National Health Insurance Database, Table S4: READ codes and ATC codes for identifying dementia outcomes in the UK Health Improvement Network database. 
Author Contributions: Conceptualization: J.-M.L. and E.C.-C.L.; methodology: J.-M.L. and E.C.C.L.; software: W.C.Y.L. and E.C.-C.L.; validation: J.-M.L. and E.C.-C.L.; formal analysis: C.-Y.S. and W.C.Y.L.; investigation: C.-Y.S. and W.C.Y.L.; resources: W.C.Y.L. and E.C.-C.L.; data curation: W.C.Y.L. and E.C.-C.L.; writing-original draft preparation: J.-M.L. and E.C.-C.L.; writing-review and editing: all authors; visualization: J.-M.L. and E.C.-C.L.; supervision: E.C.-C.L.; project administration: E.C.-C.L. All authors have read and agreed to the published version of the manuscript.

Funding: Ministry of Science and Technology of Taiwan (107-2320-B-006-070-MY3).

Institutional Review Board Statement: This study has been approved by the Institutional Review Board of National Cheng Kung University Hospital (A-ER-107-387) and the Research Ethics Committee for THIN (19THIN084).

Informed Consent Statement: Not applicable.

Data Availability Statement: The datasets used and/or analyzed during the current study are available from the corresponding author upon request.

Conflicts of Interest: The authors declare no conflict of interest.

\section{References}

1. Parker, C.; Gillessen, S.; Heidenreich, A.; Horwich, A. ESMO Guidelines Committee. Cancer of the prostate: ESMO Clinical Practice Guidelines for diagnosis, treatment and follow-up. Ann. Oncol. 2015, 26, v69-v77. [CrossRef]

2. Huggins, C.; Hodges, C.V. Studies on prostatic cancer. I. The effect of castration, of estrogen and androgen injection on serum phosphatases in metastatic carcinoma of the prostate. CA Cancer J. Clin. 1972, 22, 232-240. [CrossRef]

3. Hogervorst, E.; Combrinck, M.; Smith, A.D. Testosterone and gonadotropin levels in men with dementia. Neuroendocrinol. Lett. 2003, 24, 203-208.

4. Vest, R.S.; Pike, C.J. Gender, sex steroid hormones, and Alzheimer's disease. Horm. Behav. 2013, 63, 301-307. [CrossRef]

5. Rosario, E.R.; Chang, L.; Stanczyk, F.Z.; Pike, C.J. Age-related testosterone depletion and the development of Alzheimer disease. JAMA 2004, 292, 1431-1432. [CrossRef] [PubMed]

6. Cherrier, M.M.; Matsumoto, A.M.; Amory, J.K.; Asthana, S.; Bremner, W.; Peskind, E.R.; Raskind, M.A.; Craft, S. Testosterone improves spatial memory in men with Alzheimer disease and mild cognitive impairment. Neurology 2005, 64, $2063-2068$. [CrossRef] [PubMed]

7. Nead, K.T.; Gaskin, G.; Chester, C.; Swisher-McClure, S.; Leeper, N.J.; Shah, N.H. Association Between Androgen Deprivation Therapy and Risk of Dementia. JAMA Oncol. 2017, 3, 49-55. [CrossRef]

8. Tae, B.S.; Jeon, B.J.; Shin, S.H.; Choi, H.; Bae, J.H.; Park, J.Y. Correlation of Androgen Deprivation Therapy with Cognitive Dysfunction in Patients with Prostate Cancer: A Nationwide Population-Based Study Using the National Health Insurance Service Database. Cancer Res. Treat. 2019, 51, 593-602. [CrossRef] [PubMed]

9. Jhan, J.H.; Yang, Y.H.; Chang, Y.H.; Guu, S.J.; Tsai, C.C. Hormone therapy for prostate cancer increases the risk of Alzheimer's disease: A nationwide 4-year longitudinal cohort study. Aging Male 2017, 20, 33-38. [CrossRef] [PubMed]

10. Khosrow-Khavar, F.; Rej, S.; Yin, H.; Aprikian, A.; Azoulay, L. Androgen Deprivation Therapy and the Risk of Dementia in Patients with Prostate Cancer. J. Clin. Oncol. 2017, 35, 201-207. [CrossRef]

11. Levine, G.N.; D’Amico, A.V.; Berger, P.; Clark, P.E.; Eckel, R.H.; Keating, N.L.; Milani, R.V.; Sagalowsky, A.I.; Smith, M.R.; Zakai, N.; et al. Androgen-deprivation therapy in prostate cancer and cardiovascular risk: A science advisory from the American Heart Association, American Cancer Society, and American Urological Association: Endorsed by the American Society for Radiation Oncology. CA Cancer J. Clin. 2010, 60, 194-201. [CrossRef]

12. Ng, H.S.; Koczwara, B.; Roder, D.; Vitry, A. Development of comorbidities in men with prostate cancer treated with androgen deprivation therapy: An Australian population-based cohort study. Prostate Cancer Prostatic Dis. 2018, 21, 403-410. [CrossRef] [PubMed]

13. Robinson, D.; Garmo, H.; Van Hemelrijck, M.; Damber, J.E.; Bratt, O.; Holmberg, L.; Wahlund, L.O.; Stattin, P.; Adolfsson, J. Androgen deprivation therapy for prostate cancer and risk of dementia. BJU Int. 2019, 124, 87-92. [CrossRef] [PubMed]

14. Kao, L.T.; Lin, H.C.; Chung, S.D.; Huang, C.Y. No increased risk of dementia in patients receiving androgen deprivation therapy for prostate cancer: A 5-year follow-up study. Asian J. Androl. 2017, 19, 414-417.

15. Blak, B.T.; Thompson, M.; Dattani, H.; Bourke, A. Generalisability of The Health Improvement Network (THIN) database: Demographics, chronic disease prevalence and mortality rates. Inform. Prim. Care 2011, 19, 251-255. [CrossRef] [PubMed]

16. Hsieh, C.Y.; Su, C.C.; Shao, S.C.; Sung, S.F.; Lin, S.J.; Kao Yang, Y.-H.; Lai, E.C. Taiwan's National Health Insurance Research Database: Past and future. Clin. Epidemiol. 2019, 11, 349-358. [CrossRef]

17. Brauer, R.; Lau, W.C.Y.; Hayes, J.F.; Man, K.K.C.; Osborn, D.P.J.; Howard, R.; Kim, J.; Wong, I.C.K. Trazodone use and risk of dementia: A population-based cohort study. PLoS Med. 2019, 16, e1002728. [CrossRef] [PubMed]

18. Fairhurst, C.; Watt, I.; Martin, F.; Bland, M.; Brackenbury, W.J. Exposure to sodium channel-inhibiting drugs and cancer survival: Protocol for a cohort study using the QResearch primary care database. BMJ Open 2014, 4, e006604. [CrossRef] [PubMed] 
19. Liu, J.M.; Yu, C.P.; Chuang, H.C.; Wu, C.T.; Hsu, R.J. Androgen deprivation therapy for prostate cancer and the risk of autoimmune diseases. Prostate Cancer Prostatic Dis. 2019, 22, 475-482. [CrossRef]

20. Brookhart, M.A.; Wyss, R.; Layton, J.B.; Stürmer, T. Propensity score methods for confounding control in nonexperimental research. Circ. Cardiovasc. Qual. Outcomes 2013, 6, 604-611. [CrossRef]

21. Austin, P.C.; Lee, D.S.; Fine, J.P. Introduction to the Analysis of Survival Data in the Presence of Competing Risks. Circulation 2016, 133, 601-609. [CrossRef] [PubMed]

22. Mi, X.; Hammill, B.G.; Curtis, L.H.; Lai, E.C.; Setoguchi, S. Use of the landmark method to address immortal person-time bias in comparative effectiveness research: A simulation study. Stat. Med. 2016, 35, 4824-4836. [CrossRef]

23. Jayadevappa, R.; Chhatre, S.; Malkowicz, S.B.; Parikh, R.B.; Guzzo, T.; Wein, A.J. Association Between Androgen Deprivation Therapy Use and Diagnosis of Dementia in Men with Prostate Cancer. JAMA Netw. Open 2019, 2, e196562. [CrossRef] [PubMed]

24. Holland, J.; Bandelow, S.; Hogervorst, E. Testosterone levels and cognition in elderly men: A review. Maturitas 2011, 69, 322-337. [CrossRef] [PubMed]

25. Moffat, S.D.; Zonderman, A.B.; Metter, E.J.; Blackman, M.R.; Harman, S.M.; Resnick, S.M. Longitudinal assessment of serum free testosterone concentration predicts memory performance and cognitive status in elderly men. J. Clin. Endocrinol. Metab. 2002, 87, 5001-5007. [CrossRef]

26. Thilers, P.P.; Macdonald, S.W.; Herlitz, A. The association between endogenous free testosterone and cognitive performance: A population-based study in 35 to 90 year-old men and women. Psychoneuroendocrinology 2006, 31, 565-576. [CrossRef]

27. Sari Motlagh, R.; Quhal, F.; Mori, K.; Miura, N.; Aydh, A.; Laukhtina, E.; Pradere, B.; Karakiewicz, P.I.; Enikeev, D.V.; Deuker, M.; et al. The Risk of New Onset Dementia and/or Alzheimer Disease among Patients with Prostate Cancer Treated with Androgen Deprivation Therapy: A Systematic Review and Meta-Analysis. J. Urol. 2021, 205, 60-67. [CrossRef]

28. Nead, K.T.; Sinha, S.; Nguyen, P.L. Androgen deprivation therapy for prostate cancer and dementia risk: A systematic review and meta-analysis. Prostate Cancer Prostatic Dis. 2017, 20, 259-264. [CrossRef]

29. Krasnova, A.; Epstein, M.; Marchese, M.; Dickerman, B.A.; Cole, A.P.; Lipsitz, S.R.; Nguyen, P.L.; Kibel, A.S.; Choueiri, T.K.; Basaria, S.; et al. Risk of dementia following androgen deprivation therapy for treatment of prostate cancer. Prostate Cancer Prostatic Dis. 2020, 23, 410-418. [CrossRef]

30. Bressi, B.; Cagliari, M.; Contesini, M.; Mazzini, E.; Bergamaschi, F.A.M.; Moscato, A.; Bassi, M.C.; Costi, S. Physical exercise for bone health in men with prostate cancer receiving androgen deprivation therapy: A systematic review. Support. Care Cancer 2021, 29, 1811-1824. [CrossRef] [PubMed]

31. Bekelman, J.E.; Mitra, N.; Handorf, E.A.; Uzzo, R.G.; Hahn, S.A.; Polsky, D.; Armstrong, K. Effectiveness of androgen-deprivation therapy and radiotherapy for older men with locally advanced prostate cancer. J. Clin. Oncol. 2015, 33, 716-722. [CrossRef]

32. Holmes, L., Jr.; Chan, W.; Jiang, Z.; Du, X.L. Effectiveness of androgen deprivation therapy in prolonging survival of older men treated for locoregional prostate cancer. Prostate Cancer Prostatic Dis. 2007, 10, 388-395. [CrossRef] [PubMed]

33. Deka, R.; Simpson, D.R.; Bryant, A.K.; Nalawade, V.; McKay, R.; Murphy, J.D.; Rose, B.S. Association of Androgen Deprivation Therapy with Dementia in Men with Prostate Cancer Who Receive Definitive Radiation Therapy. JAMA Oncol. 2018, 4, 1616-1617. [CrossRef] [PubMed]

34. Baik, S.H.; Kury, F.S.P.; McDonald, C.J. Risk of Alzheimer's Disease Among Senior Medicare Beneficiaries Treated with Androgen Deprivation Therapy for Prostate Cancer. J. Clin. Oncol. 2017, 35, 3401-3409. [CrossRef]

35. Nead, K.T.; Gaskin, G.; Chester, C.; Swisher-McClure, S.; Dudley, J.T.; Leeper, N.J.; Shah, N.H. Androgen Deprivation Therapy and Future Alzheimer's Disease Risk. J. Clin. Oncol. 2016, 34, 566-571. [CrossRef]

36. Chung, S.D.; Lin, H.C.; Tsai, M.C.; Kao, L.T.; Huang, C.Y.; Chen, K.C. Androgen deprivation therapy did not increase the risk of Alzheimer's and Parkinson's disease in patients with prostate cancer. Andrology 2016, 4, 481-485. [CrossRef]

37. Cornford, P.; van den Bergh, R.; Briers, E.; Van den Broeck, T.; Cumberbatch, M.G.; De Santis, M.; Fanti, S.; Fossati, N.; Gandaglia, G.; Gillessen, S.; et al. EAU-EANM-ESTRO-ESUR-SIOG Guidelines on Prostate Cancer. Part II-2020 Update: Treatment of Relapsing and Metastatic Prostate Cancer. Eur. Urol. 2021, 79, 263-282. [CrossRef] [PubMed]

38. Cheng, T.M. Reflections on the 20th anniversary of Taiwan's single-payer National Health Insurance System. Health Aff. 2015, 34, 502-510. [CrossRef]

39. Herrett, E.; Gallagher, A.M.; Bhaskaran, K.; Forbes, H.; Mathur, R.; van Staa, T.; Smeeth, L. Data Resource Profile: Clinical Practice Research Datalink (CPRD). Int. J. Epidemiol. 2015, 44, 827-836. [CrossRef]

40. Kessler, R.C.; Bromet, E.J. The epidemiology of depression across cultures. Annu. Rev. Public Health 2013, 34, 119-138. [CrossRef] [PubMed]

41. Mendelson, W.B. A review of the evidence for the efficacy and safety of trazodone in insomnia. J. Clin. Psychiatry 2005, 66, 469-476. [CrossRef] [PubMed]

42. Fink, H.A.; MacDonald, R.; Rutks, I.R.; Wilt, T.J. Trazodone for erectile dysfunction: A systematic review and meta-analysis. BJU Int. 2003, 92, 441-446. [CrossRef] [PubMed]

43. Zhong, X.M.; Wang, F.; Zhang, Q.; Ungvari, G.S.; Ng, C.H.; Chiu, H.F.K.; Si, T.-M.; Sim, K.; Avasthi, A.; Grover, S.; et al. Concurrent benzodiazepine use in older adults treated with antidepressants in Asia. Int. Psychogeriatr. 2019, 31, 685-691. [CrossRef] [PubMed] 